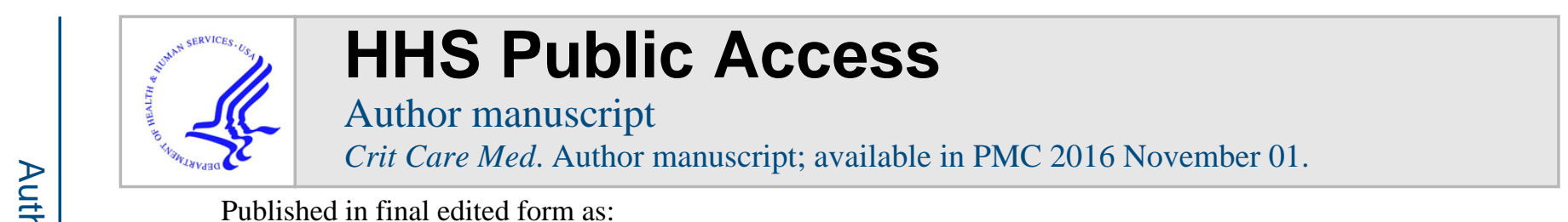

Published in final edited form as:

Crit Care Med. 2015 November ; 43(11): 2504-2506. doi:10.1097/CCM.0000000000001323.

\title{
On the Threshold of a Dream
}

\author{
Jerry J. Zimmerman, MD, PhD, FCCM [Faculty] \\ Pediatric Critical Care Medicine Seattle Children's Hospital University of Washington School of \\ Medicine FA.2.300B, 4800 Sand Point Way NE Seattle, WA 98105, Phone: 206-987-3862, Fax: \\ 206-987-3866
}

Jerry J. Zimmerman: jerry.zimmerman@seattlechildrens.org

\section{Keywords}

sepsis recognition; infection; microbial detection; polymerase chain reaction; electrospray ionization-mass spectrometry

Standard work for sepsis employing a bundled treatment approach emphasizes the need to keep an eye on the clock (1). Like trauma, there also exists a 'golden hour' for sepsis resuscitation (2). Accordingly time to initial fluid administration $(3,4)$ and time to administration of appropriate antimicrobials $(5,6)$ represent key elements of early sepsis resuscitation that are associated with improved patient outcomes. However, before sepsis can be treated, it must be recognized. Sepsis recognition and verification must occur in order to initiate implementation of the sepsis bundle. However, this process may be complicated. As one example, it has been reported that emergency physicians may underestimated likelihood of serious bacterial infection among young children with fever, resulting in under treatment with antibiotics. Conversely $20 \%$ of such children without bacterial infection were prescribed antibiotics. There is a real need for sensitive and specific, real time diagnosis of bacterial infection (7). Existing culture-based microbe identification is slow and unreliable. Particularly in the intensive care unit, false negative cultures are problematic, and are often likely associated with concurrent antibiotic treatment. Mean while, missed or delayed sepsis diagnosis is a quality issue. In this regard the article by Vincent and colleagues is intriguing to both researchers and clinicians alike (8).

The RADICAL research team compared microbe identification using a novel, polymerase chain reaction/electrospray ionization-mass spectrometry (PCR/ESI-MS) technology with standard culture-base microbiological testing. Bloodstream, pneumonia, body fluid, and tissue infections were all examined. The authors point out that PCR/ESI-MS can detect more than 800 relevant pathogens. The current work represents a logical follow-up of previously published research examining this technology (article references 9-13). In addition to pathogen identification, the technology can also identify three classes of antibiotic resistance (methicillin, vancomycin, and carbapenems). Coagulase negative staphylococcus and other common skin microbes were excluded from the overall analysis - this may be appropriate for validation of the test, but not for clinical diagnosis of sepsis particularly among immunosuppressed individuals or infants and small children. 
Employing culture as the 'gold standard', PCR/ESI-MS demonstrated a sensitivity of $81 \%$ and negative predictive value of $97 \%$ for blood stream infections. Interestingly PCR/ESIMS reported a relevant organism in 173 specimens that were culture negative, resulting in a calculated assay specificity of $69 \%$ - one could argue about the appropriate 'gold standard' relative to this sensitivity result. The PCR/ESI-MS test also appeared to perform well with bronchoalveolar lavage and endotracheal tube aspirate samples, as well as body fluid and tissue samples. Perhaps more important, results from PCR/ESI-MS were available within 6 hours from sample acquisition, permitting near real time decisions about starting, continuing or discontinuing antimicrobials. In addition, utilizing a panel of independent clinical adjudicators, the authors determined that the PCR/ESI-MS technology results might have altered sepsis treatment in nearly $60 \%$ of patients. Ability of PCR/ESI-MS to rule out infection within 6 hours has important antimicrobial stewardship implications that relate to antimicrobial resistance, occurrence of adverse reactions to antimicrobials, and a variety of costs associated with administration of antimicrobials.

Systematic review and meta-analysis (examining 41 phase III diagnostic accuracy studies for SeptiFast) of another real-time PCR technology (albeit limited microbe repertoire) for microbe identification, reported a summary sensitivity and specificity of 0.68 (95\% CI $0.63-$ 0.73 ) and 0.86 (95\% CI 0.84-0.89) respectively when compared to blood culture (9). Because of deficiencies in study quality, no firm recommendations regarding the likely clinical utility of this test were provided. Similar results have been reported for PCR-based sepsis diagnostic testing among premature infants (10). Authors of the systematic review emphasized the importance of utilizing (Standards for Reporting of Diagnostic Accuracy) STARD criteria for evaluating such technology when there is no 'gold standard' $(11,12)$.

Although the RADICAL study focused on microbe identification at onset of infection, this technology will likely also be valuable in terms of defining when it is safe to discontinue antimicrobials. This has certainly been an area of interest for other sepsis biomarkers, particularly $\mathrm{C}$ reactive protein and procalcitonin $(13,14)$. As the RADICAL authors discuss, this application will need to address the findings of sterile culture versus detection of the last vestiges of microbial structural elements. Advantages of the RADICAL 6 hour turn around time include tailoring of antimicrobials after the first dose (discontinuation, adding, deleting, substitution); institution of appropriate isolation as needed; and final discontinuation of antimicrobials.

To maximize value a new diagnostic test must not only be quality-improving, but also costlowering $(15,16)$. Facilitating antimicrobial stewardship in all of its facets is one way to improve value for sepsis treatment (17). Investigators have examined a mathematical prediction model describing the impact of PCR-based rapid tailoring of antimicrobial treatment (18). Such testing enables earlier, adequate treatment and is expected to reduce mortality. The authors estimate that cost for such testing ( $\sim 300 € /$ test) could be fully recovered for patients with daily treatment costs exceeding $717 €$.

Sepsis is initiated by a microbial pathogen eliciting a host response that usually neutralizes the invading microorganism, but frequently at the expense of considerable collateral damage termed sepsis-mediated multiple organ dysfunction syndrome. Both the microbe e.g. (8) and 
host response characteristic of sepsis e.g. $(19,20)$ can now be accurately and precisely characterized with clinically relevant turn around times. Hopefully clinicians stand at the threshold of a new diagnostic era that will include optimized sensitivity and specificity for sepsis detection and hence accelerated appropriate sepsis treatment ultimately reflecting improved sepsis outcomes.

\section{Acknowledgments}

Copyright form disclosures: Dr. Zimmerman received funding from the Seattle Children's Hospital, University of Washington, Children's University Medical Group Salary and the Society of Critical Care Medicine (Travel reimbursement to attend committee and board meetings). He received royalties from Elsevier (Coeditor of textbook, Pediatric Critical Care) and received support for travel from multiple institutions (for invited lectureships). He disclosed unlabeled product use (polymerase chain reaction/electrospray ionization-mass spectrometry [PCR/ESIMS] technology for microbial detection). His institution received funding from the National Institutes of Health (NIH), Seattle Children's Research Institute, and ImmuneXpress (Research funding).

\section{References}

1. Dellinger RP, Levy MM, Rhodes A, et al. for the Surviving Sepsis Campaign Guidelines Committee. Surviving Sepsis Campaign: International Guidelines for Management of Severe Sepsis and Septic Shock: 2012. Crit Care Med. 2013; 41:580-637. [PubMed: 23353941]

2. Cengiz P, Zimmerman JJ. Prelude to pediatric multiple organ dysfunction syndrome: the golden hours concept revisited. Pediatr Crit Care Med. 2003; 4:263-264. [PubMed: 12749669]

3. Lee SJ, Ramar K, Park JG, et al. Increased fluid administration in the first three hours of sepsis resuscitation is associated with reduced mortality: a retrospective cohort study. Chest. 2014; 146:908-915. [PubMed: 24853382]

4. Waechter J, Kumar A, Lapinsky SE, et al. Cooperative Antimicrobial Therapy of Septic Shock Database Research G. Interaction between fluids and vasoactive agents on mortality in septic shock: a multicenter, observational study. Crit Care Med. 2014; 42:2158-2168. [PubMed: 25072761]

5. Kumar A, Roberts D, Wood KE, Light B, Parrillo JE, Sharma S, Suppes R, Feinstein D, Zanotti S, Taiberg L, Gurka D, Kumar A, Cheang M. Duration of hypotension before initiation of effective antimicrobial therapyis the critical determinant of survival in human septic shock. Crit Care Med. 2006; 34:1589-1596. [PubMed: 16625125]

6. Weiss SL, Fitzgerald JC, Balamuth F, et al. Delayed antimicrobial therapy increases mortality and organ dysfunction duration in pediatric sepsis. Crit Care Med. 2014; 42:2409-2417. [PubMed: 25148597]

7. Craig JC, Williams GJ, Jones M, et al. The accuracy of clinical symptoms and signs for the diagnosis of serious bacterial infection in young febrile children: prospective cohort study of 15781 febrile illnesses. BMJ. 2010; 340:c1594. [PubMed: 20406860]

8. Vincent JL, Brealey D, Libert N, et al. the RADICAL Team. A Rapid Diagnosis of Infection in the Critically Ill (RADICAL), a multicenter study of molecular detection in bloodstream infections, pneumonia and sterile site infections. Crit Care Med. 2015 in press.

9. Dark P, Blackwood B, Gates S, et al. Accuracy of Light Cycler((R)) Septi Fast for the detection and identification of pathogens in the blood of patients with suspected sepsis: a systematic review and meta-analysis. Intensive Care Med. 2015; 41:21-33. [PubMed: 25416643]

10. Chan KY, Lam HS, Cheung HM, et al. Rapid identification and differentiation of Gram-negative and Gram-positive bacterial bloodstream infections by quantitative polymerase chain reaction in preterm infants. Crit Care Med. 2009; 37:2441-2447. [PubMed: 19531943]

11. Rutjes AW, Reitsma JB, Coomarasamy A, et al. Evaluation of diagnostic tests when there is no gold standard. A review of methods. Health technology assessment. 2007; 11:iii, ix-51. [PubMed: 18021577]

12. Bossuyt PM, Reitsma JB, Bruns DE, et al. Standards for Reporting of Diagnostic A. Towards complete and accurate reporting of studies of diagnostic accuracy: The STARD Initiative. Ann Intern Med. 2003; 138:40-44. [PubMed: 12513043] 
13. Kopterides P, Siempos II, Tsangaris I, et al. Procalcitonin- guided algorithms of antibiotic therapy in the intensive care unit: a systematic review and meta-analysis of randomized controlled trials. Crit Care Med. 2010; 38:2229-2241. [PubMed: 20729729]

14. Oliveira CF, Botoni FA, Oliveira CR, et al. Procalcitonin versus C-reactive protein for guiding antibiotic therapy in sepsis: a randomized trial. Crit Care Med. 2013; 41:2336-2343. [PubMed: 23921272]

15. Kahn JM, Angus DC. Reducing the cost of critical care: new challenges, new solutions. Am J Respir Crit Care Med. 2006; 174:1167-1168. [PubMed: 17110650]

16. Porter ME. What is value in health care? N Engl J Med. 2010; 363:2477-2481. [PubMed: 21142528]

17. Dellit TH, Owens RC, McGowan JE Jr, et al. Society for Healthcare Epidemiology of A. Infectious Diseases Society of America and the Society for Healthcare Epidemiology of America guidelines for developing an institutional program to enhance antimicrobial stewardship. Clin Infect Dis. 2007; 44:159-177. [PubMed: 17173212]

18. Lehmann LE, Herpichboehm B, Kost GJ, et al. Cost and mortality prediction using polymerase chain reaction pathogen detection in sepsis: evidence from three observational trials. Crit Care. 2010; 14:R186. [PubMed: 20950442]

19. Sutherland A, Thomas M, Brandon RA, Brandon RB, Lipman J, Tang B, McLean A, Pascoe R, Price G, Nguyen T, Stone G, Venter D. Development and validation of a novel molecular biomarker diagnostic test for the early detection of sepsis. Crit Care. 2011; 15:R149. [PubMed: 21682927]

20. Wong HR, Cvijanovich NZ, Anas N, Allen GL, Thomas NJ, Bigham MT, Weiss SL, Fitzgerald J, Checchia PA, Meyer K, Shanley TP, Quasney M, Hall M, Gedeit R, Freishtat RJ, Nowak J, Shekhar RS, Gertz S, Dawson E, Howard K, Harmon K, Beckman E, Frank E, Lindsell CJ. Developing aclinically feasible personalized medicine approach to pediatric septic shock. Am J Respir Crit Care Med. 2015; 191:309-315. [PubMed: 25489881] 